\title{
РЕГИОНАЛЬНЫЕ ИССЛЕДОВАНИЯ
}

\author{
ЗАПАДНАЯ АЗИЯ
}

УДК $327+94$

\section{Геополитическое положение Азербайджанской Республики: изменения во времени и пространстве}

\author{
А. И. Ибрагимов, Г. М. Исмайлова ${ }^{* *}$ \\ *Эгейский университет, \\ Измир, 35040, Туреикая Республика \\ **Чанаккалинский университет 18 Марта, \\ Чанаккале, 17020, Турецкая Республика
}

Для цитирования: Ибрагимов А.И., Исмайлова Г.М. Геополитическое положение Азербайджанской Республики: изменения во времени и пространстве // Актуальные проблемы мировой политики. Вып.10 / под ред. Т.С.Немчиновой. СПб.: Изд-во С.-Петерб. ун-та, 2020. С.246-260. https://doi.org/10.21638/11701/26868318.17

Развитие и трансформация геополитического положения Азербайджанской Республики рассматривается в контексте трех различных периодов. Этап первой Азербайджанской Республики (1918-1920); суверенное государство в рамках СССР (1920-1991); отрезок с 1991 г. до наших дней. Проводя сравнительный анализ геополитического положения каждого периода, можно заметить как схожие моменты, так и различия. Практически в течение последних ста лет в разных периодах развития Азербайджана прослеживаются три основные сквозные линии. Первая - неизменность основного геополитического противника в лице Республики Армении, вторая - постоянное нахождение в зоне противостояния России и Запада и третья - воздействие энергетических ресурсов на страновой статус.

Ключевые слова: Азербайджанская Республика, геополитика, изменения, различия, геополитическое поведение.

Находящаяся на побережье Каспийского моря и расположенная на перекрестке Европы и Азии, Азербайджанская Республика обладает очень выгодным географическим положением, однако геополитическое пространство в определенной степени препятствует пол- 
ной реализации имеющихся преимуществ. Являясь государством Южного Кавказа, Азербайджан уже в течение длительного времени как в региональном, так и в глобальном геополитическом и геоэкономическом контексте находится в зонах разлома.

Наблюдаются осложнения во взаимоотношениях с приграничными странами. К примеру, кризис российско-грузинских отношений привел к фактическому закрытию совместной границы, что отразилось на транзитном использовании территории Грузии в экономических и торговых связях Азербайджана с Россией. Другой пример - северная граница Азербайджана, которая проходит по реке Самур, отделяя страну от северокавказской республики Дагестан. Напряженная криминогенная обстановка в этой части Российской Федерации препятствует транспортно-экономическим связям Азербайджана с ее северным соседом ${ }^{1}$, ведь территория Российской Федерации - важный транспортный коридор в страны Центральной, Восточной и Северной Европы. В свою очередь, Азербайджан представляет собой транспортный коридор в Иран и страны Персидского Залива. Все вышесказанное предопределяет развитие связей различного типа Азербайджанской Республики с регионами Российской Федерации. И в целом Россия природно-ресурсным, человеческим и социально-экономическим потенциалом привлекательна для Азербайджана. Другим перспективным с позиций развития внешнеэкономических связей Азербайджанской Республики партнером является Исламская Республика Иран. Территория Ирана представляет для Азербайджана выход в большой регион Ближнего и Среднего Востока, к Индийскому океану и Южной Азии. Однако выгодное положение, обусловленное географией, нивелируется ограничениями, создаваемые политикой стран Запада в отношении этой прикаспийской страны.

Безусловно, самое негативное влияние на процессы социальноэкономического развития Азербайджана оказывает соседнее государство Армения, оккупировавшая 20\% территории республики. Можно говорить о нескольких последствиях такого соседства. Вопервых, это значительный экономический урон, нанесенный территориальной аннексией (около 1 млрд долл.) ${ }^{2}$. Во-вторых, моральный

${ }^{1}$ Орлов Д. Кавказский регион: политическая ситуация и конфигурация элит. https://regnum.ru/news/2256630.html.

2 Grono M., Vartanyan O. Armenia and Azerbaijan's collision course over NagornoKarabakh. https://www.opendemocracy.net/od-russia/olesya-vartanyan-magdalena- 
ущерб, нанесенный азербайджанской нации. Азербайджан является единственной страной мирового сообщества, 1/5 территории которой уже почти четверть века оккупирована соседним государством. Данное положение формирует у азербайджанского общества сознание обреченности и недоверия к международной системе безопасности, которая в случае с Арменией не проявляет должной реакции в соответствии с нормами международного права.

Первая Азербайджанская республика. Возникшее государство являлось результатом политических трансформаций в Российской империи. Первая независимая Азербайджанская республика видела себя в Кавказском геополитическом пространстве, и 22 апреля 1918 г. совместно с Арменией и Грузией была создана Кавказская Демократическая Федеративная Республика. Значительные внешние политические и внутренние противоречия сделали существование данного федеративного образования недолговечным - через месяц федерация распалась. 28 мая 1918 г. была провозглашена Азербайджанская Демократическая Республика (АДР).

Надо отметить, что элита того времени играла значительную роль в социальной жизни России. Она осознавала себя и Азербайджан лидером тюрко-исламского сообщества Советской России. Главная причина подобного крылась в сформировавшемся национальном самосознании и сравнительной приближенности к процессам европейской модернизации.

Возникшая на обломках Российской империи АДР стала первым светским государством Востока. Парламент страны представлял собой многопартийный орган, в него входили представители всех этнических групп, населяющих АДР. Было предоставлено избирательное право женщинам, свобода слова закреплена законом, началось проведение целого ряда социальных реформ.

К сожалению, мировые геополитические процессы - окончание Первой мировой войны, победа большевиков в России, вхождение Красной Армии на территорию республики, агрессивные действия Дашнакской Армении в Нагорном Карабахе и Нахичевани, противоречивая обстановка в Турции, отсутствие политической стабильности в самой республике и др. - привели к падению АДР.

Оценивая с геополитических позиций внешнюю политику АДР, надо отметить, что она была довольно взвешенной. Республика свой

grono/armenia-and-azerbaijan-collision-course-over-nagorno-karabakh 
геополитический код определяла исламской цивилизацией, общетюркской культурой и европейскими демократическими ценностями [1, p. 14].

Первое национальное государство свою геополитическую ориентацию проецировало на Европу, Кавказ и Анатолию. В тот период в Баку находилось 16 дипломатических миссий, только три из них не представляли Европу (США, Грузия и Иран). Как и сейчас, западные страны проявляли большой интерес к АДР, считали его основным партнером в регионе. Главной причиной подобного интереса были нефтяные ресурсы страны [2, p.8].

В 1918 г. границы Азербайджана соответствовали современным, он граничил с пятью государствами. Однако то время отличалось значительной нестабильностью: формировалась новая политическая карта мира и региона, Россия была охвачена гражданской войной, Османская империя доживала последние дни, патриотические силы вели борьбу за изгнание иностранных оккупантов из Анатолии, Первая мировая война только закончилась, европейские страны занимались восстановлением своих государств. Все это препятствовало социально-экономическому и политическому развитию АДР, очень сложно было с транспортировкой бакинской нефти как в страны Европы, так и основному партнеру республики Турции.

Безусловно, все вышеперечисленное отражалось и на геополитическом поведении страны, сужало пространство ее активности. Здесь можно выделить три главных фактора.

1. Закончились попытки республики Армения по расширению своего жизненного пространства за счет Анатолийских земель, и она повернула свой взор в сторону Нахичевани и Карабаха, входящих в состав АДР [3, p. 87].

2. Большевики пытались восстановить контроль над Баку и в целом над Азербайджаном как важным геополитическим и геоэкономическим узлом на путях к Ближнему и Среднему Востоку, ведущим мировым нефтяным центром.

3. Неизменный моральный оплот Азербайджана - Турция, которая хотела видеть поддержку АДР в контексте поставок бакинской нефти.

Здесь необходимо сделать небольшую ремарку. В тот период кемалистская Турция была одним из основных стратегических пар- 
тнеров Советской России на антиимпериалистическом фронте. По ряду вопросов у них были общие подходы, Азербайджан был одной из таких тем.

Вторая Азербайджанская Республика. 28 апреля 1920 г. АДР была свергнута и произошла ее советизация. Социализм утвердился во всех трех республиках Южного Кавказа, и прошло национальное размежевание как в этом регионе, так и на всем Кавказе.

В результате данного процесса заселенные азербайджанцами территории Зангезур, Дерелеез и Гойча были переданы Армении, Борчалы - Грузии. Эта политика была направлена на разрушение единого тюркского пояса в масштабе евроазиатского региона. Отметим, что общая площадь АДР составила 93,7 тыс. кв. км. Став независимой 30 декабря 1991 г., Азербайджанская Республика обладала пространством в 86,6 тыс. кв. км [4, p. 128]. С 12 марта 1922 по 5 декабря 1936 г. Азербайджан входил вместе с Арменией и Грузией в состав Закавказской Федерации и после ее распада стал одной из союзных республик, то есть продолжил существование в качестве суверенного социалистического государства в составе СССР [4, p. 135].

В период существования Советского Союза республика часть полномочий передала союзному центру и в геополитике действовала в соответствии с принципами внутренней и внешней политики CCCP.

На первом этапе социалистического строительства АзССР чувствовала себя в некотором роде наследницей АДР. В регионе и на всем пространстве Советского Союза она хотела играть специфическую геополитическую роль. В 1926 г. в Баку впервые был проведен Всесоюзный тюркологический конгресс [5, p. 10-11; 6, с. 427]. Азербайджан первым среди тюркоязычных народов перешел на латиницу ${ }^{3}$.

Политические лидеры и культурная интеллигенция (Нариман Нариманов, Гусейн Джавид, Бекир Чобанзаде и др.) видели республику не только частью Кавказа, но и всего тюркско-исламского мира $[7$, р. 80]. Проводимая культурная революция реализовывалась в этом контексте. Однако тоталитарная сталинская система отвергла подобные амбиции азербайджанского общества, и оно замкнулось и действовало в рамках, определяемых Кремлем.

${ }^{3}$ Переход Азербайджана на алфавит с латинской графикой. www.zerkalo. az/2013/perehod-azerbaydzhana-na-alfavit-s-latinskoy-grafikoy; [5; 6]. 
Именно тогда происходило оформление идентичности азербайджанских тюрков, что находило отражение в поведении национальной интеллигенции. Если мы проведем анализ геополитического сознания азербайджанского народа, то заметим значительное воздействие тюркско-исламского фактора, который был основой, как уже выше упоминалось, национального самосознания общества 4 . Подобное объясняется стремлением сохранить национальную самобытность и сформировать хотя бы в усеченном виде государственность в условиях советского социализма.

История становления Азербайджана в XX в. оказывает сильнейшее воздействие на культурно-психологический стереотип азербайджанского общества, формирует его проекцию на будущее развитие. Отметим, что наличие интернационального индустриального центра Баку в определенной степени препятствовало формированию националистической доминанты в этническом самосознании азербайджанского социума, что отличало республику от соседней Армении.

В условиях конфронтации различных идеологий и социальноэкономических систем Азербайджан играл специфическую роль в деле противостояния капитализма и социализма. В рамках геополитической парадигмы СССР Азербайджан занимал особое место в деле презентации советской аттрактивности для стран третьего мира. Он был моделью развития в культурном и в социально-экономическом плане, особенно в таких темах, как просветительское преобразование, преодоление однобокой специализации и моногоукладности. Не случайно отцы-основатели Советского Союза называли республику воротами Востока ${ }^{5}$. Особую значимость придавало значительное количество национальных кадров в деле странового управления, что могло быть хорошим опытом для развивающихся стран, где эта проблема была особо актуальна. По количественному составу национальных кадров в системе партийных и советских органов Азербайджан был на лидирующих позициях среди других республик Советского Востока. Особенно это усилилось в конце 60-х - начале 70-х годов ХХ в. [8, p.93].

Во внутренней геополитике СССР Азербайджан также в соответствии с географическим положением и потенциалом экономиче-

${ }^{4}$ Gömeç S. Türk Tarihinin KahramanlarıLII: Mehmet Emin Resulzade, ORKUN, 117 Sayı, Kasım, 2007.

${ }^{5}$ Коммунистический режим в Северном Азербайджане / Портал Фонда Гейдара Алиева. www.azerbaijan.az/portal/History/Middle/middle_05_r.html. 
ских ресурсов играл достаточно важную роль. Республика всесоюзным центром рассматривалась с трех позиций.

1. Несмотря на падение значимости нефтяной составляющей (в 1940-х годах Азербайджан обеспечивал до 40 \% потребности страны в нефти, в 80-х годах данный показатель упал до $2 \%)$, Баку продолжал оставаться нефтяной столицей СССР, в республике производилось до 80 \% оборудования для скважин [9, с.186]. Здесь находилось командование Бакинского округа ПВО, охватывавшего гигантскую территорию от Средней Азии до Уральских гор [10].

В Баку было расположено командование Каспийской флотилии; Азербайджан был ведущей республикой на побережье Каспийского моря, которому определялась роль смотрителя Каспия. Здесь находились Каспийское морское пароходство, осуществляющее перевозки по Каспию, и объединение Каспморнефтегазпром, являвшееся ответственным за поиск и добычу углеводородного сырья по всей акватории моря.

Особую значимость в геостратегическом отношении Азербайджану в годы Великой Отечественной войны придавало то, что Баку был основной топливной базой Советского Союза и внес значительный вклад в дело победы над фашистской Германией.

2. Азербайджану была предоставлена особая роль в Кавказском регионе СССР. Причина крылась в значительном промышленном потенциале республики, выводящем его на первое место в Закавказском экономическом районе. В отличие от соседних республик, здесь было огромное количество предприятий союзного подчинения [11, с.97]. Азербайджан являлся главным транспортным узлом Кавказа, здесь проходили транспортные пути в Центральную Азию и Средний Восток.

3. В религиозном и этническом отношении Азербайджан соседствовал с родственными ему государствами Ираном и Турцией, которым советское руководство придавало особую значимость (безусловно, со всеми положительными и отрицательными последствиями).

Вторая Азербайджанская Республика, даже обладая усеченным суверенитетом, находясь в постоянном конкурентном состоянии 
с соседями на Южном Кавказе, проводила геополитику, направленную на защиту национальных интересов.

Если Грузия и Армения обладали значительным политическим весом в связи с их глубокой интеграцией в управленческий и социокультурный истеблишмент СССР, то Азербайджанская ССР находила место под солнцем путем кропотливого труда во благо советской экономики, часто во вред своим национальным интересам. Это выражалось в непомерно высоких нормах сбора хлопка, винограда и овощей, полном загрязнении нефтяных ареалов на суше и приведении в непригодное состояние, создании зон, опасных для проживания населения ввиду сверхкритичной загазованности, и т.д. [12].

Вторая Азербайджанская Республика просуществовала 70 лет. Изменение глобальных векторов развития и внутренние процессы в СССР привели в итоге к развалу этой державы и образованию ряда новых независимых государств.

Для Азербайджана этот процесс был довольно болезненным и сложным, республика потеряла контроль над более чем 20 \% своей территории и вступила в этап независимого развития в разбалансированном состоянии с большим количеством социально-экономических и политических проблем. Если в ряде регионов мы видели противостояние в политической системе - партийно-государственный аппарат и новая демократия, то в Азербайджане существовала некая четырехмерность проблем. К традиционному перестроечному противостоянию между властью и оппозицией добавился внутренний этнический сепаратизм, инициированный соседней республикой, поддержанный демократической элитой центра и благосклонностью союзного руководства. Подобная критическая масса оказалась тяжелой ношей для страны, привела к деформациям в политическом развитии общества, последствия которых ощущаются до сих пор.

Третья Азербайджанская Республика. 18 октября 1991 г. Азербайджан после развала СССР объявил о независимости, считая себя правопреемником Азербайджанской Демократической Республики, образованной 28 апреля 1918 г. Оставаясь страной Южного Кавказа, являясь важным энергетическим хабом на пути из Каспийского региона в Западную Европу, он ощущает себя трансрегиональным государством.

Вместе с тем глобальные геополитические центры наряду с восприятием Азербайджана как представителя Южного Кавказа 
и тюркско-исламского мира рассматривают его в качестве органической части Азиатского региона и тем самым противопоставляют двум соседним христианским государствам - Армении и Грузии, что вызывает раздражение в азербайджанском обществе.

Тем не менее несколько общих черт объединяют три южно-кавказские республики. Во-первых, они в качестве отдельных национальностей совместно сосуществовали в Российской империи, в дальнейшем - суверенных республик в составе СССР. Во-вторых, народы, формирующие данные государства, избирательно подходят к национальному статусу. Грузия всячески подчеркивает желание стать частью европейской цивилизации, Армения презентует себя миру как первое христианское сообщество, Азербайджан выступает в качестве самого светского и толерантного образования Востока. В-третьих, существует проблема нестабильной территориальной целостности трех южно-кавказских республик. Если Грузия и Азербайджан временно потеряли контроль над частью территории, то Армения, оккупировав территории соседнего государства, де-факто включила их в свои границы и обладает пространством, не признаваемым за ней мировым сообществом.

С геополитической точки зрения положение Азербайджанской Республики отличается от двух государств. Азербайджан помимо южно-кавказских соседей граничит с тремя государствами - Российской Федерацией, Турецкой Республикой, Исламской Республикой Иран. Грузия граничит с Россией и Турцией, Армения с Ираном и Турцией. То есть из всех стран Южного Кавказа только Азербайджан имеет границы со всеми геополитическими игроками региона. Помимо этого имеет выход на Каспийское побережье, посредством чего вступает в контакт со странами Центральной Азии, что делает страну привлекательной в геополитическом и геоэкономическом отношении. Появление транспортной магистрали Баку - Тбилиси Карс усилит эти позиции.

При оценке геополитического положения Азербайджана становится ясным, что он зажат между важными игроками региона: Ираном, Россией и Турцией. Двое из них амбициозные, третий сосед Россия - является одной из глобальных сил мира и сам определяет тренды поведения.

Вместе с тем всех троих можно считать государствами, находящимися в постоянном поиске своего места в мире. Российская Федерация борется за былое могущество времен СССР, две другие 
страны стремятся изменить свой геополитический статус путем противостояния с западом и рядом стран региона. Иран, пытаясь демонстрировать исламскую особенность и отличие от западных демократий, стремится преодолеть одиночество в регионе, обусловленное принадлежностью к шиитской ветви ислама. Турция, начиная с 2002 г., значительно изменив внешне- и внутриполитический крен, трансформировала линию геополитического поведения (корни которого уходят в 1991 г. - период развала СССР и возникновения целой группы тюркоязычных государств) и начала проводить независимый курс относительно стран Среднего Востока и Евразийского пространства [13, с. 200].

Наиболее сложным для Азербайджана является соседство с Apменией. Карабахский вопрос можно считать основным фактором, воздействующим на все геополитическое поведение страны. На постсоветском пространстве еще три государства находятся в схожем состоянии (потеря суверенитета на части территории), однако наблюдаются значительные различия в ситуации.

Если у партнеров по ГУАМ (Грузия, Украина, Азербайджан, Молдавия) в качестве визави выступает один из глобальных геополитических игроков современности, то в случае с Азербайджаном это стратегический союзник Российской Федерации по Организации Договора о коллективной безопасности и Евразийскому экономическому союзу - Республика Армения, идеологической основой которой является национальная идея, где существенное место отводится учению Гарегина Нжде «Цегакрон» (этнорелигиозное учение националистического толка. - $\mathrm{Aвm}$. $)^{6}$.

Второе отличие заключается в многовекторности Карабахского конфликта. Если в других случаях мы наблюдаем противостояние сепаратистского региона с центральной властью, в нашем происходит столкновение на трех уровнях. С одной стороны, сепаратистский регион, с другой - Республика Армения, с третьей - обладающая значительной политической силой диаспора.

Третье отличие в том, что Запад в Карабахской ситуации ведет себя равноудаленно от сторон конфликта и не выступает однозначно в поддержку территориальной целостности Азербайджана, при этом в случаях с остальными членами ГУАМ открыто поддерживает

${ }^{6}$ Website of the Republican Party of the Republic of Armenia. http://www.hhk.am/ en/program. 
их государственную целостность и не возлагает ответственность на обе стороны конфликта [14, с. 127].

Четвертая, пожалуй, главная отличительная черта заключается в том, что страна представляет единственный случай на постсоветском пространстве, где восставший регион перешел этнические и административные границы, оккупировав прилегающие к нему территории республики.

Все перечисленное осложняет весь комплекс взаимоотношений между республикой и Евроатлантическим сообществом, которое, в отличие от Грузии и Армении, ментально не воспринимает Азербайджан частью западного мира.

На наш взгляд, особый подход мировых держав к Карабахскому вопросу обусловлен цивилизационным фактором. Нагорный Карабах на политической карте мира является единственным христианским образованием, находящимся в административном подчинении мусульманского государства.

Азербайджанская Республика в отличие от других государств, входящих в ГУАМ, ведет уравновешенную внешнюю политику, не вступает в открытый конфликт и выстраивает с одной из ведущих мировых держав - Российской Федерацией - особые отношения стратегического характера7.

Азербайджан находится на перекрестке путей различных культур и цивилизаций, играет роль своеобразного моста между Западом и Востоком. Страна является активным участником динамических процессов, протекающих в региональных геополитических секторах. Это и Кавказ в целом, и его южная часть в особенности, соседское положение с Грузией, Россией и Турцией, что делает его приближенным к проблемам Черноморского региона; а турецкое и иранское пограничье вовлекает страну в динамику Среднего Востока.

Нельзя сбрасывать со счетов прикаспийский статус, который имеет архиважное значение. Здесь наиболее рельефно проявляется основной потенциал геоэкономического положения страны. В отличие от других государств Каспия историческое и социально-экономическое развитие Азербайджана связано с этим внутренним бассейном. С Каспийским морем сопряжено новое явление Азер-

7 Тегеран-2017: итоги визита Владимира Путина. https://www.vesti.ru/doc.html $\mathrm{id}=2949885$. 
байджана миру. C первых дней независимости республика стала проводить особую каспийскую геостратегию. Во внутреннем водоеме столкнулись интересы пяти государств - Азербайджана, Ирана, Казахстана, России, Туркменистана, которые уже много лет пытаются их разрешить путем переговоров. Процесс длительный и сложный, является предметом особого исследования и не входит в круг интересов данной статьи.

Фактор нефти и газа стал точкой опоры новой азербайджанской геополитики, это содействует постепенной трансформации республики из государства регионального значения в страну со значительным межрегиональным геополитическим содержанием ${ }^{8}$.

Таким образом, Азербайджанская Республика - динамичная и быстро меняющаяся в пространстве и времени система. Нефть и особенное расположение в регионе (границы с главными геополитическими игроками, Каспийское море и пр.) являются краеугольными камнями геостратегического и геоэкономического поведения.

Если первая республика стала заложницей общемировой ситуации и потеряла независимость, то вторая, используя ресурсный потенциал и геоэкономический статус, была одной из определяющих республик Советского Союза и сумела войти в независимое состояние, сохранив первую государственную идентичность.

В период независимого развития Азербайджан начал себя позиционировать как европейское государство с восточным содержанием. В нынешнем кризисном мире подобная точка зрения приобретает особую значимость, и Азербайджанская Республика, находясь в точке пересечения цивилизаций Запада и Востока, может в короткий срок пройти необходимый путь европейской модернизации, сохранив восточную сущность, что и будет основой для формирования модели геополитического поведения республики в первой половине XXI в.

\section{Литература}

1. Dliyev V. Azərbaycan Bayrağı. Bakı: Yazıcı, 2011.

2. Çəmənzəminli Y. Xarici siyasətimiz. Bakı: Azərnəşr, 1993.

3. Afanasiyan S. Ermənistan, Azərbaycan, Gürcüstan istiqlaldan sovet rejiminin qurulduğu dönəmə qədər: 1917-1923 / пер.с фарси. Bakı: Qanun, 2012.

${ }^{8}$ Сайт Президента Азербайджанской Республики. http://www.president.az/articles/25789. 
4. Azərbaycan tarixi: 7 ciddə / AMEA A. A. Baкıxanov adına Tarix İnstitutu.VI cild. Вак1: Elm, 2000.

5. Первый Всесоюзный тюркологический конгресс. Стенографический отчет // Baku: Nagyl Evi, 2011.

6. Немчинова Т. С., Музалёв А. А. Влияние языковой политики на формирование общего образовательного пространства в государствах Центральной Азии // Евразийский юридический журнал. 2018. № 3 (118). С. 426-430.

7. Dliyeva F.N. Norimanov va Oil complex of the Caspian region: problems of functioning and development Milli Məsələ. Bakı: Nafta Press, 2015.

8. Həbibbəyli I. Heydər Oliyev dövlətçilik təlimi və müasir dövr, Nahçivan, Әcəmi NPB, 2011.

9. Исмаилов С. Нефтяной комплекс Прикаспийского региона: проблемы функционирования и развития. Баку: Изд-во Бакинского гос. ун-та, 2000. 214 с.

10. Бакинский округ противовоздушной обороны [Текст]: Исторический очерк (1920-1974) / ред. А. У. Костантинов. Баку: Азернешр, 1974. 363 с.

11. Мир-Бабаев М. Краткая история азербайджанской нефти. Баку: Азернешр, 2007. 376 c.

12. Israfilov S. Environment and Natural Resources Protection. http://www.aplr.org/ conference/en/experts_papers.

13. Ягъя В.С. Турция в современной системе мировой политики // Актуальные проблемы мировой политики в XXI веке: Сб. статей / под ред. В.С.Ягъя, М. Л. Лагутиной. СПб.: Изд-во С.-Петерб. ун-та, 2011. 520 с.

14. Мехтиев Р. Миропорядок двойных стандартов и современный Азербайджан. Баку: Шарг-Гарб, 2015. 224 с.

15. Стрелков А. Политика Евросоюза в постсоветском регионе // Евросоюз и Россия: политика на постсоветском пространстве / Научный журнал ИНИОН РАН. Актуальные проблемы Европы. 2011. № 2. С.9-38.

Контактная информация:

Ибрагимов Айдьн И. - д-р геогр. наук, проф.; aydin.ibrahimov@mail.ege.edu.tr Исмайлова Галина М. — канд. юрид. наук, доц.; gulzarismail@comu.edu.tr

\section{Geopolitical Location of the Republic of Azerbaijan: temporal and Spatial Changes}

Aydin I. Ibrahimov

Ege University, Izmir, Turkey

\section{Gulzar M. Ismaylova}

Chanakkale 18 Mart University, Turkey

For citation: Ibrahimov A.I., Ismaylova G. M. Geopolitical Location of the Republic of Azerbaijan: temporal and Spatial Changes. Digest of World Politics, vol.10, ed. by T.S. Nemchinova, St. Petersburg, St. Petersburg State Uni- 
versity Press, 2020, pp. 246-260. https://doi.org/10.21638/11701/26868318.17 (In Russian)

For instance, the evolution of the Republic of Azerbaijan was examined in three different periods. The first one is the republican period (1918-1920); the second one is the sovereign state period (1920-1991); and the third one is the period since 1991. Each period was compared with the others and the similarities and differences experienced in the geopolitics of the country were evaluated. Three main lines are clearly seen in the geopolitics conducted approximately throughout the last century by different Azerbaijans. Firstly, the main geopolitical competitor is the Republic of Armenia; secondly, the competition taking place in the region between Russia and the West creates the atmosphere which influences the geopolitical behaviors; and thirdly, the fixed element which determines the status of the country is the energy resources.

Keywords: Republic of Azerbaijan, geopolitics, geopolitical behavior, change, different.

\section{References}

1. Oliyev V. Azarbaycan Bayră̆ı. Bakı: Yazıcı, 2011.

2. Çəmənzəminli Y. Xarici siyasətimiz. Bakı: Azərnəşr, 1993.

3. Afanasiyan S. Ermanistan, Azarbaycan, Gürcüstan istiqlaldan sovet rejiminin qurulduğu dönəmə qadər: 1917-1923. Bakı: Qanun, 2012.

4. Azarbaycan tarixi: 7 ciddə / AMEA A. A. Вакıxanov adına Tarix İnstitutu.VI cild. Вакı: Elm, 2000.

5. First All-Union Turkic Congress. Stenograficheskii otchet. First All-Union Congress of Turkic. Verbatim report. Baku: Nagyl Evi, 2011.

6. Nemchinova T.S., Muzalev A. A. The impact of language policy on the creation of educational space in Central Asia. Evrazijskii yuridicheskii zhurnal, 2018, no. 3 (118), pp. 426-430. (In Russian).

7. Oliyeva F. N. Narimanov va Oil complex of the Caspian region: problems of functioning and development Milli Masala. Bak1: Nafta Press, 2015.

8. Həbibbəyli I. Heydar Oliyev dövlatçilik təlimi va müasir dövr, Nahçivan, Әcəmi NPB, 2011.

9. Ismailov C. Oil complex of the Caspian region: problems of functioning and development. Baku, Baku State University Press, 2000. 214 p. (In Russian)

10. Baku District Air Defense. Historical essays / 1920-1974. Baku, Azerneshir Publ., 1974. 363 p. (In Russian).

11. Mir-Babaev M. Brief History of Azerbaijani Oil. Baku: Azerneshir. Baku, Azerneshir Publ., 2007. 376 p. (In Russian)

12. Israfilov S. Environment and Natural Resources Protection. http://www.aplr.org/ conference/en/experts_papers.

13. Jagja V. Turkey in the Modern System of World Politics. Aktualnye problemy mirovoj politiki v XXI veke: Sb. Statei. Ed. V.S. Jagja, M. L. Lagutinoi. St. Petersburg, St. Petersburg State University Press, 2011. 520 p. (In Russian) 
14. Mehtiev R. World Order of Double Standards and Modern Azerbaijan. Baku, ShargGarb Publ., 2015. (In Russian)

15. Strelkov A. EU Policy in the Post-Soviet region. Evrosojuz i Rossija: Politika na postsovetskom prostranstve. Iss. 2, Nauchnyi Zhurnal, RAN INION Publ., 2011, pp. 9-38. (In Russian)

Author's information:

Aydin I. Ibrahimov - PhD Sci. in Geography, Professor;

aydin.ibrahimov@mail.ege.edu.tr

Gulzar M. Ismaylova - PhD Sci. in Law, Assistant Professor;

gulzarismail@comu.edu.tr 